\title{
CONTROLE SOCIAL DA ADMINISTRAÇÃO PÚBLICA POR AGENTES PRIVADOS: AVALIANDO O IMPACTO DOS OBSERVATÓRIOS SOCIAIS NAS DESPESAS DOS MUNICÍPIOS DO PARANÁ
}

\author{
Renato Nunes de Lima Seixas * \\ Marllon da Silva Banhos ${ }^{\dagger}$
}

\begin{abstract}
Resumo
Este artigo tem como objetivo avaliar a eficácia da iniciativa privada no controle da administração pública. Estimamos o impacto da introdução dos Observatórios Sociais (OS) em diversas categorias de gastos públicos municipais no estado do Paraná. Utilizando informações do período 2002-2017, implementamos uma estratégia de diferenças-em-diferenças baseada na introdução gradual dos OS em um conjunto de municípios no estado do Paraná. Os resultados mostram economias em despesas com material de consumo e serviços contratados de pessoas jurídicas de até 0,5\% do PIB municipal, que tendem a serem maiores com o tempo de atuação. Concluímos que iniciativas de controle social independentes do poder público podem ser efetivas no controle da administração pública.
\end{abstract}

Palavras-chave: bens públicos, corrupção, gestão fiscal.

Códigos JEL: D02, D04, D73.

\begin{abstract}
This paper aims to evaluate the effectiveness of the private initiative in controlling public administration. We estimated the impact of the introduction of Observatórios Sociais (OS) on various categories of municipal public spending in the state of Paraná. Using information from 20022017, we implemented a strategy of differences-in-differences based on the gradual introduction of OS in a set of municipalities in the state of Paraná. The results showed savings in expenses with consumables and services contracted from legal entities of up to $0.5 \%$ of municipal GDP, which tend to be greater with time of operation. We conclude that social control initiatives independent of public authorities can be effective in controlling public administration.
\end{abstract}

Keywords: public goods, corruption, fiscal management. JEL codes: D02, D04, D73.

DOI: http://dx.doi .org/10.11606/1980-5330/ea162776

\footnotetext{
*UFES/GPE. E-mail: renato.seixas@ufes.br (autor para correspondência)

† UFES. E-mail: marllon.s.banhos@gmail.com
} 


\section{Introdução}

A corrupção é um mal que vem despertando crescente preocupação de autoridades e da sociedade civil em âmbito global. Desde 1983, a International AntiCorruption Conference ${ }^{1}$ vem reunindo chefes de estado, líderes da sociedade civil e do setor privado em um fórum de discussão da agenda anticorrupção. No Brasil, em particular, é recorrente o aparecimento de casos ruidosos envolvendo todas as esferas de poder: executivo, legislativo e judiciário. Como consequência, o Brasil tem tido lugar cativo nos rankings internacionais de percepção de corrupção. Na mais recente edição do Índice de Percepção da Corrupção ${ }^{2}$, elaborado pela ONG Transparência Internacional, o Brasil figura na $106^{\mathrm{a}}$ colocação de um total de 198 países avaliados, tendo obtido o pior escore da série histórica iniciada em 2012.

Na administração pública subnacional, a corrupção nos 5.570 municípios brasileiros é particularmente preocupante devido à grande descentralização de recursos sob a responsabilidade de administradores locais sujeitos a diferentes graus de fiscalização. O município de Januária, norte do estado de Minas Gerais, por exemplo, teve nada menos do que sete prefeitos no período de 2004 a 2008, todos afastados por irregularidades na administração (Oliva 2012). Em reportagem recente ${ }^{3}$, estima-se que o total de recursos desviados de municípios entre 2015 e 2017 tenha atingido a cifra de R\$ 10 bilhões. São desvios que, apesar de não serem noticiados pela grande imprensa, atingem uma parcela mais vulnerável da população por se concentrarem nas regiões de menor nível de desenvolvimento econômico e social.

Do ponto de vista econômico, a corrupção é um tema de estudo relevante que tem sido abordado tanto em relação às características institucionais que favorecem seu aparecimento, aos mecanismos de combate criados pela sociedade e aos prejuízos dela decorrentes (Olken \& Pande 2012, Banerjee et al. 2013). A compreensão dos efeitos reais da corrupção vem mudando ao longo dos anos. Em teoria, a corrupção poderia representar apenas uma redistribuição do excedente, sem perdas reais, ou mesmo um mecanismo de aumento da eficiência que permitiria aos indivíduos superar entraves burocráticos ou políticas públicas equivocadas (Aidt 2003). No entanto, as evidências sugerem que os custos de eficiência na forma de taxas de imposto marginais mais altas das empresas, atividade empresarial diminuída, custos marginais mais elevados de fundos públicos, projetos governamentais tornados economicamente inviáveis e perda da capacidade do governo de corrigir externalidades atribuíveis à corrupção podem ser bastante elevados (Olken \& Pande 2012).

Um dos instrumentos mais disseminados de combate à corrupção é o monitoramento da atividade da burocracia pública que encontra respaldo tanto do ponto de vista teórico (Becker \& Stigler 1974, Banerjee et al. 2013) quanto em resultados concretos (Di \& Schargrodsky 2003, Olken 2007) ${ }^{4}$. Devido ao caráter de bem público dessa atividade, sua provisão descentralizada tende a ser menor do que o socialmente ótimo (Samuelson 1954, Bergstrom et al. 1986).

\footnotetext{
${ }^{1}$ https://iaccseries.org/about/

${ }^{2}$ https://transparenciainternacional.org.br/ipc/

${ }^{3}$ http://www.uol/noticias/especiais/cidade-pequena-corrupcao-grande-norte.htm

${ }^{4}$ Outras formas de combate à corrupção documentadas são o pagamento de salários mais elevados que introduz um mecanismo de incentivo do tipo "salário eficiência" (Van Rijckeghem \& Weder 2001, Di \& Schargrodsky 2003) e acesso à informação sobre atividades da burocracia pública (Reinikka \& Svensson 2011)
} 
Controle social da administração pública por agentes privados: avaliando o impacto dos observatórios sociais nas despesas dos municípios do Paraná 95

Por essa razão, sua execução é frequentemente deixada a cargo de órgãos públicos de controle, que também estão sujeitos aos seus próprios problemas de incentivos (Moe 2013). Desafiando essa falha de mercado, algumas iniciativas por parte de comunidades têm aparecido como resposta à falta de efetividade da ação pública no combate à corrupção (Dixit 2018, Burai 2020). Movimentos como "zero-rupee note", na Índia, e "Addiopizzo" na Italia são exemplos de iniciativas que surgem como uma reação comunitária a situações de corrupção endêmicas e têm sido objeto de estudo na literatura (Superti 2009, Battisti et al. 2018).

O presente artigo busca investigar a questão da eficácia de iniciativas privadas de monitoramento da administração pública e combate à corrupção na produção de economias nas despesas públicas municipais. Nossa abordagem parte das constatações de que maiores níveis de corrupção tornam a prestação de serviços públicos mais caros, o que se reflete em maior volume de gastos (Caldas et al. 2016), e menos eficiente em termos de entrega de serviços para a sociedade (Ferraz et al. 2012, Lewis 2017). Em particular, estimamos o impacto dos Observatórios Sociais (OS) municipais, que são coordenados pela rede "Observatório Social do Brasil" (OSB), sobre as despesas públicas dos municípios no estado do Paraná. Para identificar o efeito causal da atuação dos OSs nos municípios, fazemos uso da introdução gradual dessas unidades nos municípios em diferentes momentos do tempo no período 2006-2017. Assim, seguimos a linha de outros trabalhos que examinam o efeito de políticas de combate à corrupção, por meio de maior monitoramento da atividade pública, sobre uma das principais consequências da corrupção: o encarecimento da contratação de bens e serviços (Di \& Schargrodsky 2003, Olken 2007).

Desde a criação do Programa de Fiscalização por Sorteios Públicos da Controladoria Geral da União (CGU), vários pesquisadores têm se debruçado sobre diferentes aspectos da microeconomia da corrupção no Brasil (Ferraz \& Finan 2008, 2011, Ferraz et al. 2012, Brollo et al. 2013, Caldas et al. 2016, Campos \& Pereira 2016, Campos et al. 2018). Os efeitos do monitoramento e divulgação de práticas corruptas foram estudados por Ferraz \& Finan (2008) que concluem que os eleitores reagem à revelação de resultados de auditorias externas punindo nas urnas prefeitos que são flagrados cometendo irregularidades na gestão de fundos transferidos pelo governo federal. Já os efeitos da corrupção sobre volume de gastos e qualidade de serviços entregues à sociedade foram estudados por Caldas et al. (2016) e Ferraz et al. (2012), respectivamente, que encontram relação positiva entre corrupção e volume de gastos e negativa entre corrupção e qualidade dos serviços prestados em educação. Nosso trabalho se relaciona com essa literatura e inova ao estudar o efeito de uma iniciativa privada de monitoramento de contas públicas e combate à corrupção sobre despesas municipais no Brasil.

No contexto de outros países em desenvolvimento, outros trabalhos examinaram questões parecidas com a nossa. Em uma análise experimental conduzida na Indonésia (Olken 2007), não foram encontrados efeitos significativos da inspeção da comunidade local em projetos de obras públicas. Outra análise experimental conduzida em Uganda (Björkman \& Svensson 2009) encorajou a participação em ambientes comunitários para aumentar o envolvimento da população com o estado da prestação de serviços de saúde e a capacidade de responsabilizar os provedores locais por seu desempenho. Os resultados documentam um aumento da utilização de serviços de saúde, redução da mortalidade infantil e aumento do peso das crianças. Finalmente, outro estudo 
envolvendo reuniões comunitárias convocadas por representantes do governo local na Índia documenta uma maior participação nessas reuniões de membros de grupos sociais desprivilegiados e um melhor enfoque de programas sociais nas localidades aonde esses encontros ocorrem (Besley et al. 2005). Assim, nosso trabalho também inova em relação à literatura internacional ao examinar o efeito de uma organização de maior escala em um contexto de desenvolvimento institucional também distinto.

Os resultados encontrados mostram economias significativas nas rubricas de despesas com material de consumo e serviços contratados de pessoas jurídicas, sujeitas à atividade de monitoramento de compras públicas pelos OSs, que podem alcançar somas de até $0,5 \%$ do PIB dos municípios. Além disso, encontramos efeitos diferenciados por tempo de atuação dos OSs. Concretamente, OSs com mais experiência, i.e. , maior tempo de atuação, produzem maiores economias. Para rubricas que não estão sujeitas à atuação dos OSs, tais como diárias, gasto com pessoal, pagamento de juros e amortizações, não encontramos nenhum efeito. Interpretamos esse resultado como evidência de que os efeitos estimados não refletem outras variáveis omitidas que poderiam estar confundindo o real impacto da atividade dos OSs.

O restante do artigo está organizado da seguinte forma. A seção dois faz uma descrição da rede OSB e de suas frentes de atuação. A seção três descreve os dados utilizados na análise. A seção quatro discute a estratégia empírica. A seção cinco discute os resultados das estimações e a seção seis sumariza as principais conclusões.

\section{A Rede "Observatório Social do Brasil" e Fiscalização de Contas Municipais}

A rede Observatório Social do Brasil é uma instituição não governamental, sem fins lucrativos e apartidária, que tem seu início no ano de 2006, no estado do Paraná, quando consolida o então Observatório Social criado em 2004 na cidade de Maringá (PR) ${ }^{5}$. A entidade atua na forma de associação de Observatórios Sociais (OS) municipais e usa uma metodologia própria de monitoramento de contas públicas ${ }^{6}$, a partir da publicação de editais de licitações até a entrega dos produtos finais, desenvolvida a partir de treinamento junto a órgãos oficiais de controle e fazendo uso de instrumentos dados pela "Lei da Transparência" e pela "Lei de Acesso a Informação" (Michener et al. 2018). Além do monitoramento de licitações, o OSB também possui as seguintes frentes de ação: educação fiscal ${ }^{7}$, estímulo à participação de micro e pequenas empresas em processos licitatórios e consolidação e divulgação de indicadores de gestão pública ${ }^{8}$. O OSB capacita e fornece suporte aos OS locais estabelecendo parcerias estaduais e nacionais.

A constituição de um OS municipal parte da inciativa de articulação dos cidadãos que fazem o primeiro contato com a rede OSB. Após uma etapa ini-

\footnotetext{
${ }^{5}$ Criada sob a denominação "Sociedade Eticamente Responsável", a partir da mobilização de cidadãos após a descoberta de desvios de aproximadamente R 100 milhões no período de 1997 2000. Passou ser denominada Observatório Social de Maringá no ano de 2006, quando iniciou as atividades de controle das contas públicas. Fonte: http://observatoriosocialmaringa.org.br/faqperguntas-e-respostas/, acessado em 26/04/2019.

${ }^{6}$ Lei Complementar no 131/2009 e lei 12.527/2011.

${ }^{7} \mathrm{http}: / /$ escoladacidadania.osbrasil.org.br/

${ }^{8}$ http://osbrasil.org.br/indicadores-de-gestao-publica/
} 
Controle social da administração pública por agentes privados: avaliando o impacto dos observatórios sociais nas despesas dos municípios do Paraná 97

cial de entrevistas e primeiras instruções, tem início o processo de instalação e registro da unidade, bem como sua filiação à rede OSB que fornece padrão de identidade visual, manuais de procedimentos, sistemas informatizados, capacitação inicial e suporte técnico permanente ${ }^{9}$.

Em 2020, a rede OSB está sediada em Curitiba (PR) e possui 150 observatórios filiados em 17 estados, contando com o trabalho de mais de 3.500 voluntários financiados por uma rede de mantenedores e apoiadores institucionais. A natureza voluntária e apartidária dos colaboradores coloca desafios para a organização (Bona \& Boeira 2018). Em particular, a profissionalização do quadro técnico e a sustentabilidade financeira da organização são tidas como dificuldades à atuação da rede. Em muitos casos, as unidades não possuem funcionários ou possuem menos de cinco funcionários (Favretto \& Riccio 2017). Mesmo com uma estrutura limitada, a organização estima que, entre 2013 e 2019, o sistema OSB teria contribuído com uma economia de R\$ 4 bilhões aos cofres públicos ${ }^{10}$.

Segundo o Tribunal de Contas da União ${ }^{11}$, a responsabilidade da fiscalização das contas públicas está apoiada nos órgãos oficiais do governo, que devem controlar e monitorar a alocação dos recursos e garantir o cumprimento de suas regras. Com relação aos municípios, essa fiscalização fica a cargo de órgãos oficiais, como a CGU, que fiscaliza a alocação dos recursos federais repassados aos municípios e os Tribunais de Contas, responsáveis pela análise das contas nacionais, estaduais e municipais. Para esse fim, coexistem o Tribunal de Contas da União (TCU), os Tribunais de Contas dos Estados (TCE) e os Tribunais de Contas dos Municípios (TCM). No entanto, desde a Constituição de 1988, é vedada a criação de novos órgãos, Tribunais ou Conselhos relacionados às contas municipais, embora não tenha impedido a manutenção do funcionamento daqueles que já estivessem criados até então. Assim, apenas os municípios de São Paulo e Rio de Janeiro possuem hoje Tribunais de Contas Municipais atuando no julgamento de suas próprias contas. Todos os outros municípios brasileiros têm suas contas avaliadas pelos TCEs e pela CGU, no que se refere à aplicação de recursos federais. A partir do ano 2000, a Lei de Responsabilidade Fiscal fez obrigatória a criação de Unidades de Controle Interno nos órgãos de todos os poderes e esferas de governo, sem especificar, no entanto, o tamanho mínimo ou o nível de gastos mínimos nessas atividades ${ }^{12}$

No entanto, a capilaridade dos mais de 5.000 municípios brasileiros abre a possibilidade de que essa fiscalização por órgãos centralizados não seja efetiva. Isso pode ser devido a diversos fatores, tais como: disponibilidade limitada de recursos por parte dos TCEs, que podem não ser suficientes para exercer o devido controle de todos os municípios situados em seus respectivos territórios, elevadas distâncias entre municípios, baixa extensão territorial ou pouca relevância econômica de municípios de pequeno porte. Além dessas possibilidades, há evidências de que os TCEs são relativamente isolados de mecanismos de controle social por falta de transparência, apesar dos avanços permitidos pela "Lei de Responsabilidade Fiscal" e "Lei de Acesso à Informação" (Rocha et al. 2020). Essa situação sugere que pode haver espaço para a

\footnotetext{
${ }^{9}$ http://osbrasil.org.br/como-constituir-um-os/

${ }^{10}$ https://osbrasil.org.br/o-que-e-o-observatorio-social-do-brasil-osb/

${ }^{11} \mathrm{https} / / /$ portal.tcu.gov.br/ouvidoria/duvidas-frequentes/fiscalizacao-das-prefeituras.htm

${ }^{12} \mathrm{https} / /$ politica.estadao.com.br/blogs/gestao-politica-e-sociedade/a-incapacidade-dascontroladorias-municipais-antes-e-depois-da-pandemia/
} 
atuação complementar de outras entidades da sociedade civil na fiscalização das contas públicas. Em paralelo, desde a criação da Lei de Responsabilidade fiscal, o ordenamento jurídico brasileiro vem criando mecanismos de acesso a informações referentes à administração pública, no sentido de aumentar a transparência da sua gestão para além dos órgãos de controle oficiais (Zuccolotto \& Teixeira 2019). Dessa maneira, a formação e a atuação de OSs nos municípios, especialmente os de menor porte, podem preencher uma possível carência de fiscalização externa existente nos mesmos.

Alguns exemplos de atuação da rede de OSs podem ser úteis para ilustrar a descrição do trabalho da rede. Em Julho de 2020, em meio à pandemia do Coronavírus, o OS de São Caetano do Sul (SP) identificou aditivo de $\mathrm{R} \$ 400 \mathrm{mil}$ em contrato entre a câmara municipal e uma empresa de comunicação por um período de 12 meses. Após pedir vistas do procedimento administrativo e constatar que este estava em desacordo com a legislação eleitoral que veda publicidade institucional nos três meses antecedentes a eleição, o OS encaminhou pedido à Câmara Municipal para que o contrato fosse anulado, avisando que, em caso de indeferimento sem justificativa, os fatos seriam encaminhados ao Ministério Público para apuração ${ }^{13}$. Em Arapongas (PR), no ano de 2020, a unidade do OS elaborou relatório detalhado sobre a aplicação de recursos públicos no combate à pandemia de Covid-19. O "Boletim Covid-19" contém informações sobre receitas recebidas da União e do estado em função do Covid-19, os tipos de processos licitatórios utilizados, para aquisição de produtos em função do Covid-19, e relatório detalhado de gastos relacionados à pandemia ${ }^{14}$.

\section{Dados}

O artigo faz uso de dados para os municípios paranaenses de diversas fontes. Para estimar o impacto dos OSs nas despesas municipais, utilizamos informações consolidadas pela Secretaria do Tesouro Nacional do Ministério da Economia. O período considerado na análise vai de 2002 a 2017 para todos os municípios. Depois de excluir aqueles com observações ausentes e a capital do estado, Curitiba ${ }^{15}$, ficamos com um conjunto de dados compreendendo 312 municípios e 16 anos $^{16}$.

As despesas totais são divididas em despesas "Correntes"e de "Capital". O primeiro grupo é dividido em: "Pessoal", "Juros" e "Outras" despesas primárias. Dentro do grupo "Outros", observamos os subgrupos "Material de Consumo", "Material Distribuído Gratuitamente", "Serviços de Terceiros de Pessoas Físicas" e "Serviços de Terceiros de Pessoas Jurídicas" e "Diárias". As despesas de capital são divididas em despesas de "Amortização" e "Investimentos". Este último é subdividido em "Equipamentos e Material Permanente" e "Construção e Instalações". A Tabela 1 abaixo ilustra essa divisão de rubricas de despesas. A razão para usar categorias mais desagregadas é capturar

\footnotetext{
${ }^{13}$ https://saocaetanodosul.osbrasil.org.br/?p=2159\&fbclid=IwAR0SdNLqsPSVlk1QazR3cCV ZOm3I9g8rg6bVMGDG-bXKt_zKKLLd-dNNPXg

${ }^{14}$ https://osbrasil.org.br/gastos-em-enfrentamento-ao-covid-19-em-arapongas-ate-o-mes$08 /$

${ }^{15}$ A capital Curitiba foi excluída da amostra por ser um município de grande importância política e econômica no estado e, por essa razão, atrai maior atenção da mídia e órgãos de controle oficiais. Essa exclusão não altera os resultados obtidos significativamente.

${ }^{16}$ Informações obtidas no site: http://comparabrasil.com/
} 
Controle social da administração pública por agentes privados: avaliando o impacto dos observatórios sociais nas despesas dos municípios do Paraná 99

os efeitos dos OSs sobre os itens de despesas sujeitos a processos licitatórios, que são o objeto do principal trabalho de supervisão dos OSs. Todavia, algumas das rubricas selecionadas não estão sujeitas à atuação típica dos OSs, tais como: despesas de pessoal, juros, diárias e amortizações. Por essa razão, essas variáveis são usadas na análise como uma checagem de robustez dos resultados. Caso sejam encontrados efeitos dos OSs sobre essas variáveis, isso se deverá a outras variáveis omitidas que estão correlacionadas com a presença dos OSs e simultaneamente com essas variáveis. Em outras palavras, a estimação do efeito dos OSs sobre essas rubricas funcionaria como um "teste de placebo" do tratamento que desejamos saber o efeito. Todos os valores foram corrigidos pela inflação pelo IGP-M anual, produzido pela Fundação Getúlio Vargas (FGV), e dividido pela população estimada dos municípios em cada ano produzida pelo Instituto Brasileiro de Geografia e Estatística (IBGE).

Tabela 1: Organização das Contas Municipais

\begin{tabular}{l|l|l}
\hline Despesa & \multicolumn{1}{|c|}{ Grupo } & \multicolumn{1}{c}{ Subgrupo } \\
\hline \multirow{4}{*}{ Corrente } & Pessoal & \multicolumn{1}{c}{-} \\
\cline { 3 - 3 } & Juros & - \\
\cline { 3 - 3 } & \multirow{4}{*}{ Outras } & Material de Consumo \\
\cline { 3 - 3 } & & Material Distribuído Gratuitamente \\
\cline { 3 - 3 } & & Serviços de Terceiros de Pessoas Físicas \\
\cline { 3 - 3 } & & Serviços de Terceiros de Pessoas Jurídicas \\
\cline { 3 - 3 } & & Diárias \\
\hline \multirow{3}{*}{ Capital } & \multirow{2}{*}{ Investimento } & Equipamento e Material Permanente \\
\cline { 3 - 3 } & & Construção e Instalações \\
\hline
\end{tabular}

Fonte: Elaboração própria.

A relação dos municípios com unidades do OSB foi obtida no último relatório de contas da instituição. O relatório não inclui a data de início de cada unidade. No entanto, o site da OSB disponibiliza contatos por telefone e email para cada unidade. Essas informações nos permitiram mapear quando cada um deles entrou em operação ${ }^{17}$. A Tabela 2 mostra a implementação gradual dos OSs nos municípios paranaenses no período de 2006 a 2018.

Os OSs estão presentes em 36 municípios do Paraná, que é o estado com maior número de unidades no país ${ }^{18}$. As unidades mais recentes são as de Jandaia do Sul e Prudentópolis, inauguradas em 2018. Como os dados de gastos municipais estão disponíveis até 2017, essas duas unidades não foram inclúídas na análise. Também foram excluídas algumas unidades com observações faltantes para as variáveis de interesse, o que nos deixou com uma amostra de 28 municípios tratados, i.e., $9 \%$ dos municípios da amostra. A figura 1 mostra a distribuição espacial dos municípios com presença do OSB no território do estado do Paraná.

Além dessas variáveis, os modelos estimados incluem controles para administrações municipais e filiação política do prefeito durante o período de análise. Especificamente, o período de 2002 a 2017 cobre cinco mandatos: 2001-2004, 2005-2008, 2009-2012 e 2013-2016 e 2017-2020. As informações

\footnotetext{
${ }^{17}$ Esta informação foi posteriormente confirmada pela unidade sede do sistema OSB.

${ }^{18}$ Seguido por Santa Catarina (32), São Paulo (23) e Rio Grande do Sul (15). Os demais estados com presença do OSB possuem menos de 10 unidades.
} 
Tabela 2: Implementação dos OSs no Estado do Paraná (2006 a 2018).

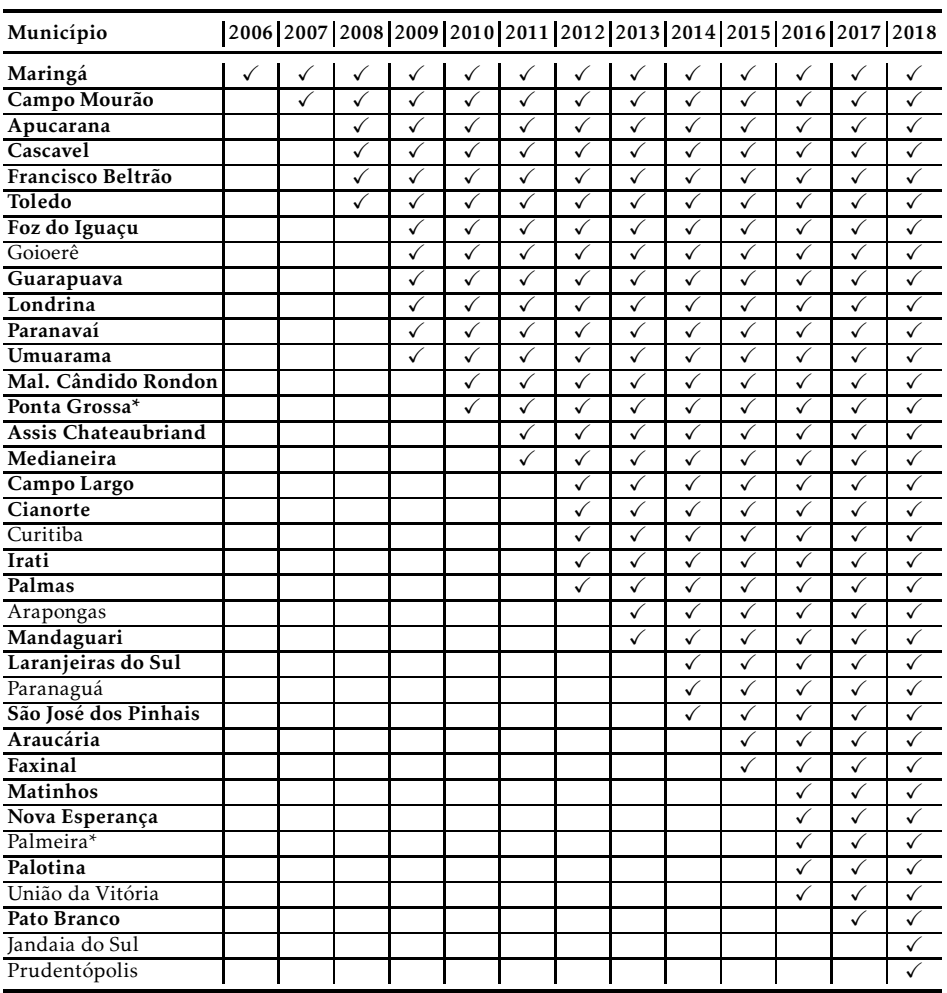

Fonte: Elaboração própria. Municípios participantes da amostra em negrito.

*Parte do OSB da região de "Campos Gerais"

Figura 1: Distribuição Territorial dos Municípios com Observatórios Sociais (vermelho).

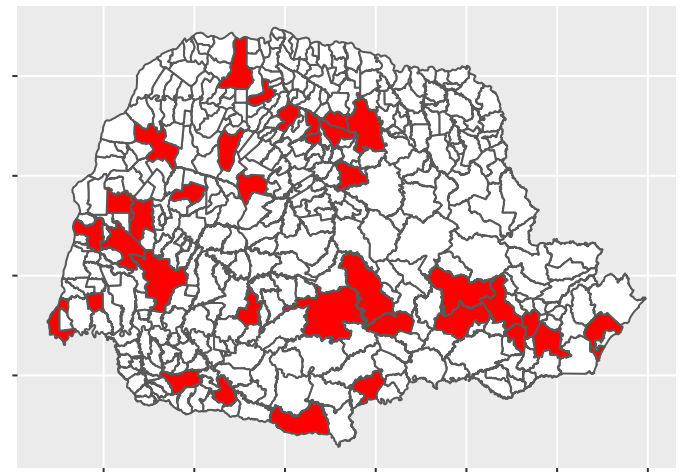

Fonte: Elaboração própria. 
Controle social da administração pública por agentes privados: avaliando o impacto dos observatórios sociais nas despesas dos municípios do Paraná 101

sobre prefeitos em exercício e filiação política foram obtidas a partir do resultado das eleições municipais disponibilizado pelo Tribunal Superior Eleitoral.

Por fim, usamos informações socioeconômicas a fim de comparar o perfil dos municípios com OSs (tratados) com os municípios sem OSs (controle). Para isso, usamos as seguintes informações: PIB municipal, população, distribuição do valor adicionado por atividade econômica (agricultura, indústria, serviços e administração pública), arrecadação de impostos, e distância à capital Curitiba, obtidas junto ao IBGE, e IDHM (total e para educação, longevidade e renda), expectativa de vida e expectativa de anos de estudo, obtidos no Atlas do Desenvolvimento Humano no Brasil (PNUD et al. 2013) ${ }^{19}$.

\section{Estratégia Empírica}

A estimação do efeito causal dos OSs sobre as despesas dos municípios deve levar em consideração a natureza não experimental da introdução dos OSs nos municípios. No caso específico dos OSs, a constituição de um observatório em uma cidade deve partir da iniciativa de seus cidadãos e de seu interesse em promover atividades de controle da administração pública. Assim, características não observáveis dos municípios podem influenciar tanto a criação de um OS quanto a qualidade da gestão fiscal do município. Por exemplo, se a população de um determinado município possui preferências políticas que favorecem a conduta rigorosa da administração pública, isso pode influenciar positivamente tanto na escolha de gestores mais competentes quanto na mobilização de um grupo de pessoas interessadas em implantar um OS. Nesse caso, essa variável omitida resultaria em viés de baixa na comparação entre as médias dos gastos: a gestão fiscal tenderia a ser melhor na economia de recursos ("fazer mais com menos") nos municípios com OS, em parte em resposta às preferências políticas da população do município. Portanto, a existência dessa e outras variáveis omitidas fazem com que a estimação do efeito dos OSs pela comparação de municípios com e sem OS seja poluída pelo viés de seleção de municípios para o tratamento (Imbens \& Wooldridge 2009).

Uma vez que não é possível realizar um experimento controlado que distribua OSs de maneira aleatória entre os municípios, é necessário utilizar uma estratégia que possa isolar outros efeitos, observáveis e não observáveis, que possam vir a confundir o efeito que se procura estimar. No presente artigo, fazemos uso da implantação gradual dos OSs em diferentes municípios e anos para implementar uma estratégia de diferenças-em-diferenças para estimar o efeito causal dos OSs sobre as despesas públicas municipais (Imbens \& Wooldridge 2009). O modelo econométrico estimado pode ser escrito da seguinte forma:

$$
y_{i t}=\alpha+\gamma_{i}+\lambda_{t}+\delta O S_{i t}+\theta X_{i t}+\sum_{i} \beta_{i}\left(\text { Municpio }_{i} \times t\right)+u_{i t}
$$

Nessa equação, cada variável dependente $\left(y_{i t}\right)$ no município i e no ano $t$ está relacionada a uma variável dummy que indica a presença do OS no município e no ano $\left(O S_{i t}\right)$, efeitos fixos para municípios, efeitos fixos para anos, uma tendência linear específica a cada município e um vetor de variáveis de

\footnotetext{
${ }^{19}$ http://www.atlasbrasil.org.br/
} 
controle $\left(X_{i t}\right)$. O coeficiente $\delta$, representa uma estimativa do efeito da introdução do OS sobre a variável dependente. A inclusão dos efeitos fixos e das tendências lineares permite controlar os efeitos de variáveis não observadas e que estejam correlacionadas com a implementação dos OSs e com as variáveis dependentes. Dessa maneira, podemos atenuar o viés causado pela omissão dessas variáveis sobre o coeficiente de interesse.

As variáveis de controle incluídas correspondem a efeitos fixos para a administração de cada município em cada mandato correspondente ao período de análise. No período de 2004-2016 tivemos três mandatos municipais. Portanto, incluímos no vetor $X_{i t}$ uma variável dummy para cada prefeito, para o partido do prefeito, e uma interação entre o prefeito e o mandato específico. A dummy de prefeitos captura efeitos da capacidade gerencial específica a cada administrador do município. A segunda variável captura efeitos decorrentes da orientação ideológica de cada partido. Já a terceira variável captura incentivos distintos que prefeitos em primeiro mandato e segundo mandato podem ter na condução da administração dos municípios (Ferraz \& Finan 2011). Também incluímos variáveis de controle que deslocam a demanda por serviços públicos e que podem ser correlacionadas com a presença dos OSs, a saber: PIB per capita e distribuição do valor adicionado nos setores de agropecuária, indústria e serviços.

Adicionalmente, também estimamos a equação um usando formas mais flexíveis para o efeito dos OSs. A primeira especificação alternativa considera o número de anos que o OS está na cidade. Dessa forma, o efeito total depende de quantos anos o OS está presente no município. Uma segunda especificação alternativa especifica a variável OS como um conjunto de variáveis dummy indicando a quantidade de anos que o OS está presente no município. Temos assim a seguinte especificação:

$$
y_{i t}=\alpha+\gamma_{i}+\lambda_{t}+\sum_{j=1}^{12} \delta_{j} O S B_{i t}^{j}+\theta X_{i t}+\sum_{i} \beta_{i}(\text { Municpio } i \times t)+u_{i t}
$$

Todas as especificações utilizam desvios-padrão robustos (Arellano 1987) e agrupados por município (Bertrand et al. 2004). Para as rubricas sob influência da atividade de fiscalização de licitações exercida pelos OSs, esperamos obter coeficientes negativos e significativos, indicando economia de recursos. Já para as demais rubricas, esperamos obter resultados não significativos, uma vez que para essas a atuação dos OSs seria um mero placebo.

\section{Resultados}

\subsection{Análise Descritiva}

A Tabela 3 mostra as estatísticas descritivas das variáveis de despesas municipais analisadas e dos indicadores socioeconômicos dos 312 municípios da amostra entre 2002 e 2017. Os indicadores de participação do valor adicionado pela atividade econômica mostram maior participação na agricultura e serviços, com a indústria atrás da administração pública. Em relação aos indicadores de desenvolvimento humano municipal, os números encontram-se abaixo da média nacional para o ano de 2010 e mostram um nível médio de desenvolvimento, segundo os critérios do Atlas do Desenvolvimento Humano 
Controle social da administração pública por agentes privados: avaliando o impacto dos observatórios sociais nas despesas dos municípios do Paraná 103

do Brasil (PNUD et al. 2013), mas com grande dispersão. Os indicadores de expectativa de vida e o índice de Gini médios para os municípios estão abaixo da média nacional, enquanto a expectativa de anos de estudo encontra-se acima da média nacional. A medida de distância geodésica média até a capital foi de $312 \mathrm{~km}$.

A Tabela 4 traz uma comparação das mesmas variáveis entre os municípios com unidades OSB (tratados) e sem unidades OSB (controle) para os anos anteriores ao início da instituição (2006). Os indicadores mostram uma grande heterogeneidade no perfil dos municípios em cada grupo. Os municípios tratados têm maior PIB (total e per capita), receita tributária (total e per capita), população e participação da indústria e serviços no valor adicionado. Os municípios do grupo de controle têm maior participação do valor adicionado na agricultura e na administração pública. Notamos também que os municípios tratados apresentam níveis mais baixos de gastos públicos per capita em quase todas as categorias. As exceções são juros e serviços de terceiros contratados a pessoas jurídicas, para os quais o grupo tratado gasta mais do que o grupo de controle, e amortização e investimentos em obras e instalações para os quais não há diferença estatisticamente significativa entre os dois grupos. Essas constatações sugerem que a seleção para o tratamento tende a ser enviesada na direção de municípios mais parcimoniosos com a despesa pública, apesar de mais ricos em termos de renda per capita, talvez devido às preferências do eleitorado por melhores gestores nesses municípios. Essas diferenças indicam um grande potencial para a ocorrência de vieses na comparação do desempenho fiscal entre os dois grupos de municípios relacionados ao efeito de variáveis omitidas.

Em relação aos indicadores de desenvolvimento humano, não existem diferenças estatisticamente significativas entre os dois grupos. As medidas de IDHM, expectativa de vida, expectativa de anos de estudo e índice de Gini são bastante próximas para os municípios com e sem presença de OS. O mesmo se aplica às distâncias geodésicas até a capital Curitiba.

\subsection{Resultados Econométricos}

As Tabelas 5,6 e 7 resumem os resultados encontrados para as três especificações do modelo econométrico. A maioria dos resultados para presença de OSs (Tabela 5) mostra um sinal negativo mas não é estatisticamente significativa. No modelo com anos de OSs em cada município (Tabela 6), também não encontramos coeficientes estatisticamente significativos para nenhuma despesa. Na terceira especificação, que separa os OSs por tempo de atuação (Tabela 7), verificamos alguns resultados significativos e positivos sobre a variável juros e resultados negativos sobre as variáveis outras despesas correntes, para OSs com um ano de atuação, despesas de capital e despesas com investimentos para OSs com 12 anos de atuação, i.e., o OS de Maringá, onde se iniciou a rede OSB. As estimativas apontam para uma economia anual de $\mathrm{R} \$ 63,37$ per capita para as despesas correntes, $\mathrm{R} \$ 1.082,17$ per capita para despesas de capital e R \$ 859,76 per capita para despesas de investimento.

Considerando a população média dos municípios no período de atuação do OS, essa economia corresponderia a um total anual de $\mathrm{R} \$ 8,2$ milhões em despesas correntes, $\mathrm{R} \$ 395,8$ milhões em despesas de capital e $\mathrm{R} \$ 314,4 \mathrm{mi}$ lhões em despesas de investimento ou $0,16 \%, 2,88 \%$ e $2,32 \%$ do PIB municipal médio de 2006 a 2017. Esse resultado sugere que a atuação dos OS demora 


\begin{tabular}{|c|c|c|c|c|c|}
\hline Variável & $\mathrm{N}$ & Média & Min & Max & Desv. Pad. \\
\hline Despesa Total (R\$/hab.) & 4.992 & $2.820,99$ & 886,51 & $14.130,26$ & $1.231,74$ \\
\hline Despesa Corrente $(\mathrm{R} \$ / \mathrm{hab})$. & 4.992 & $2.439,22$ & 717,07 & $11.674,22$ & $1.051,23$ \\
\hline Juros (R $\$ /$ hab.) & 4.992 & 16,67 & 0,00 & 413,45 & 24,47 \\
\hline Outras DC (R $\$ /$ hab.) & 4.992 & $1.164,58$ & 117,80 & $8.415,76$ & 540,09 \\
\hline Material de Consumo (R $\$ /$ hab.) & 4.992 & 410,95 & 0,00 & $2.631,12$ & 240,81 \\
\hline Material de Distribuição Gratuita (R\$/hab.) & 4.992 & 40,61 & 0,00 & 591,13 & 52,48 \\
\hline Serviços de Terceiros - Pessoa Física (R $\mathbf{\text { hab.) }}$ & 4.992 & 64,62 & 0,00 & $3.346,57$ & 85,58 \\
\hline Serviços de Terceiros - Pessoa Jurídica (R $\$ /$ hab.) & 4.992 & 457,25 & 0,00 & $3.132,21$ & 270,75 \\
\hline Diárias ( $R \$ / h a b)$. & 4.992 & 10,82 & 0,00 & 165,90 & 14,27 \\
\hline Pessoal (R\$/hab.) & 4.992 & $1.257,97$ & 208,30 & $5.418,99$ & 573,01 \\
\hline Despesas de Capital (R $\$ /$ hab.) & 4.992 & 380,58 & 4,16 & $3.410,46$ & 283,03 \\
\hline Amortização (R\$/hab.) & 4.992 & 60,09 & 0,00 & $1.712,83$ & 49,42 \\
\hline Investimento ( $R$ \$ hab.) & 4.992 & 314,24 & 0,00 & $3.117,24$ & 266,56 \\
\hline Equipamento e Material Permanente ( $\mathrm{R} \$ / \mathrm{hab}$.) & 4.992 & 93,36 & 0,00 & 826,73 & 101,10 \\
\hline Obras e Instalações ( $\mathrm{R} \$ /$ hab.) & 4.992 & 172,89 & 0,00 & $2.280,37$ & 196,11 \\
\hline PIB (R \$ milhões) & 4.992 & 718,58 & 17,38 & $33.123,46$ & $2.256,60$ \\
\hline PIB Per Capita ( $\mathrm{R} \$ 1000)$ & 4.992 & 25,35 & 6,33 & 310,02 & 17,71 \\
\hline Impostos ( $\mathrm{R} \$$ milhões) & 4.992 & 87,84 & 0,55 & $9.583,40$ & 437,26 \\
\hline Impostos Per Capita ( $\mathrm{R} \$ 1000)$ & 4.992 & 1,87 & 0,18 & 35,07 & 2,37 \\
\hline População (1000 hab.) & 4.992 & 22,41 & 1,37 & 558,44 & 50,76 \\
\hline VA Agricultura (\%) & 4.992 & 31,94 & 0,02 & 82,29 & 16,02 \\
\hline VA Indústria (\%) & 4.992 & 15,32 & $-14,07$ & 96,87 & 15,04 \\
\hline VA Serviços (\%) & 4.992 & 33,44 & 0,99 & 96,95 & 11,97 \\
\hline VA Administração (\%) & 4.992 & 19,30 & 1,06 & 43,43 & 6,89 \\
\hline IDH Municipal & 624 & 0,65 & 0,42 & 0,82 & 0,07 \\
\hline IDH Municipal-Educação & 624 & 0,53 & 0,19 & 0,77 & 0,11 \\
\hline IDH Municipal-Longevidade & 624 & 0,79 & 0,68 & 0,87 & 0,04 \\
\hline IDH Municipal-Renda & 624 & 0,66 & 0,51 & 0,85 & 0,06 \\
\hline Expectativa de Vida & 624 & 72,16 & 66,01 & 77,17 & 2,60 \\
\hline Expectativa de Anos de Estudo & 624 & 10,22 & 6,11 & 12,83 & 1,05 \\
\hline Gini & 624 & 0,50 & 0,33 & 0,71 & 0,07 \\
\hline Distância Curitiba $(\mathrm{Km})$ & 312 & 324,93 & 8,32 & 534,60 & 129,97 \\
\hline
\end{tabular}

Fonte: Elaboração própria. 
Controle social da administração pública por agentes privados: avaliando o impacto dos observatórios sociais nas despesas dos municípios do Paraná 105

Tabela 4: Comparação de Municípios (Tratados x Controle)

\begin{tabular}{|c|c|c|c|c|}
\hline Variável & Tratados & Controle & $\mathbf{t}$ & p-valor \\
\hline Despesa Total (R $\$ /$ hab.) & $1.659,18$ & $2.116,548$ & 7,054 & 0,000 \\
\hline Despesa Corrente $(\mathrm{R} \$ /$ & $1.428,992$ & $1.819,571$ & 6,874 & 0,000 \\
\hline Juros (R $\$ /$ hab.) & 17.019 & 13.638 & -2.461 & 0.015 \\
\hline Outras DC (R\$/hab.) & 691,255 & 936,208 & 8,169 &, 000 \\
\hline Material de Consumo (R $\$ /$ hab.) & 162,169 & 398,145 & 26,547 & 000 \\
\hline Material de Distribuição Gratuita (R\$/hab.) & 13,41 & 21,123 & 4,185 & 0,000 \\
\hline Serviços de Terceiros - Pessoa Física (R \$/ & 36,354 & 72,581 & 11,137 & 0,000 \\
\hline Serviços de Terceiros - Pessoa Jurídica (R $\$ /$ hab.) & 372,038 & 317,03 & $-2,759$ & 0,007 \\
\hline Diárias ( $\mathrm{R} \$ /$ hab.) & 2,252 & 6,903 & 10,455 & 0,000 \\
\hline Pessoal (R $\$ /$ hab.) & 720,717 & 869,724 & 4,862 & 0,000 \\
\hline itol ( $\mathrm{RS} / \mathrm{h}$ hb) & 230,189 & 296,977 & 5,297 & 0,000 \\
\hline Am & 52,658 & 57,839 & 2 & 0,047 \\
\hline & 171,313 & 229,496 & 5,223 & 0,000 \\
\hline al Permanente (R\$/hab.) & 14,928 & 31,237 & 6,362 & 0,000 \\
\hline Obras e Ins & 59,303 & 55,787 & $-0,428$ & 0,669 \\
\hline PIB $(\mathrm{R} \$ \mathrm{~m}$ & $3.470,138$ & 235,396 & $-8,323$ & 0,000 \\
\hline PIB Pe & 26,13 & 19,467 & $-4,459$ & 0,000 \\
\hline Impos & 496,082 & 20,142 & $-6,019$ & 0,000 \\
\hline Impo & 3,462 & 1,253 & $-5,615$ & 0,000 \\
\hline & 116 & & -9 & 000 \\
\hline & 535 & 999 & 27,356 & 000 \\
\hline VA I & 28,323 & 14,121 & $-10,197$ & 0,000 \\
\hline VA Serviço & 47,974 & 29,909 & $-19,374$ & 0,000 \\
\hline VA Admir & 13,168 & 18,971 & 14,479 & 0,000 \\
\hline IDH Mu & 0,593 & 0,594 & 0,066 & 0,947 \\
\hline & 0,446 & 0,454 & 0,431 & 0,669 \\
\hline $\mathrm{IDH} \mathrm{Mu}$ & 0,751 & 0,751 & 0,006 & 0,995 \\
\hline IDH 1 & 0,63 & 0,622 & $-0,775$ & 0,444 \\
\hline & 70,076 & 70,077 & 0,003 & 0,997 \\
\hline Expectativa de Anos de Estudo & 9,746 & 9,901 & 0,706 & 0,485 \\
\hline Gini & 0,556 & 0,539 & $-1,501$ & 0,143 \\
\hline Distância Curitiba $(\mathrm{Km})$ & 314,356 & 325,97 & 0,387 & 0,701 \\
\hline
\end{tabular}

Fonte: Elaboração própria.

mais a surtir efeitos em rubricas de maior complexidade como despesas de capital e investimentos. No entanto, por se tratar de apenas um município em um ano (2017), não podemos descartar que esse efeito seja decorrente de um choque idiossincrático que tenha afetado essas rubricas no município de Maringá no ano de 2017.

Tabela 5: Impacto dos Observatórios Sociais Sobre Despesas Municipais (1)

\begin{tabular}{ccccccccc}
\hline & Total & Correntes & Juros & Outras & Pessoal & Capital & Amort. & Invest. \\
\hline OS & $-84,282$ & $-49,582$ & 0,579 & $-58,560$ & 8,399 & $-28,219$ & 1,126 & $-20,282$ \\
& $(58,921)$ & $(50,509)$ & $(1,457)$ & $(35,833)$ & $(28,921)$ & $(31,210)$ & $(7,669)$ & $(31,788)$ \\
\hline $\mathrm{N}$ & 4.992 & 4.992 & 4.992 & 4.992 & 4.992 & 4.992 & 4.992 & 4.992 \\
$\mathrm{R}^{2}$ & 0,711 & 0,760 & 0,638 & 0,671 & 0,826 & 0,502 & 0,545 & 0,489 \\
\hline
\end{tabular}

Fonte: Elaboração própria. Notas: ${ }^{*} \mathrm{p}<0,1 ;{ }^{* *} \mathrm{p}<0,05 ;{ }^{* * *} \mathrm{p}<0,01$

Controles: efeitos fixos para municípios, anos, prefeitos,interações entre prefeitos e mandatos, partidos políticos do prefeito, PIB per capita, percentual do valor adicionado em agropecuária, indústria e serviçoos e tendências lineares por município. Erros-padrão agrupados por município. 
Tabela 6: Impacto dos Observatórios Sociais Sobre Despesas Municipais (2)

\begin{tabular}{lcccccccc}
\hline & Total & Correntes & Juros & Outras & Pessoal & Capital & Amort. & Invest. \\
\hline \multirow{2}{*}{ OS (anos) } & $-17,579$ & $-2,839$ & $2,066^{*}$ & $-19,259$ & 14,354 & $-11,026$ & $-1,590$ & $-2,339$ \\
& $(34,699)$ & $(29,398)$ & $(1,176)$ & $(18,993)$ & $(16,446)$ & $(14,293)$ & $(2,765)$ & $(14,143)$ \\
\hline $\mathrm{N}$ & 4.992 & 4.992 & 4.992 & 4.992 & 4.992 & 4.992 & 4.992 & 4.992 \\
$\mathrm{R}^{2}$ & 0,711 & 0,760 & 0,638 & 0,671 & 0,826 & 0,502 & 0,545 & 0,489 \\
\hline
\end{tabular}

Fonte: Elaboração própria. Notas: ${ }^{*} \mathrm{p}<0,1 ;{ }^{* *} \mathrm{p}<0,05 ;{ }^{* * *} \mathrm{p}<0,01$

Controles: efeitos fixos para municípios, anos, prefeitos,interações entre prefeitos e mandatos, partidos políticos do prefeito, PIB per capita, percentual do valor adicionado em agropecuária, indústria e serviçoos e tendências lineares por município.

Erros-padrão agrupados por município.

A fim de obter resultados para rubricas mais diretamente afetadas pelos processos licitatórios sob análise dos OSs, procede-se à análise com itens de maior nível de desagregação. Assim, estimamos modelos para os itens: "Material de Consumo", "Material de Distribuição Gratuita", "Serviços de Terceiros de Pessoas Físicas", "Serviços de Terceiros de Pessoas Jurídicas" e "Diárias", componentes de despesas primárias, e "Equipamentos e Material Permanente" e "Obras e Instalações", componentes das despesas de investimento. Os resultados estão resumidos nas Tabelas 8, 9 e 10 .

Para as duas primeiras especificações, os resultados obtidos para as rubricas de despesas mais desagregadas seguem o padrão anterior. O modelo com a variável OS representando a presença no município apresenta resultados não significativos. Já no modelo com a variável expressa em termos de anos presente no município, o único resultado significativo ocorreu para a rubrica Investimentos em Equipamentos, porém com sinal positivo, o contrário do esperado. A Tabela 10 mostra os resultados para o modelo com a variável OS especificada como dummy indicando o número de anos que o OS está no município. Como pode ser visto abaixo, temos vários resultados significativos e com o sinal negativo esperado, indicando que a atuação dos OSs têm, de fato, produzido algumas economias nas despesas dos municípios.

As economias proporcionadas pela atuação dos OSs se deram nas rubricas material de consumo e serviços de terceiros de pessoas jurídicas. Com relação à primeira, vemos coeficientes significativos para quase todos os anos de atuação, exceto os anos 2, 4 e 5. A evolução das economias ao longo do tempo mostra que elas são crescentes com os anos de atuação dos OS, partindo de um mínimo de $\mathrm{R} \$ 11,5$ per capita no primeiro ano de atuação até $\mathrm{R} \$ 153,3$ per capita no $12^{\circ}$ ano. Considerando as populações médias e o PIB dos municípios, essas economias equivalem a $\mathrm{R} \$ 14,2$ milhões em média para cada ano de atuação ou a 0,2\% do PIB dos municípios. Os resultados para os anos de atuação individuais estão expostos na Tabela 11 .

Com relação à rubrica serviços contratados de pessoas jurídicas, as economias estimadas pela atuação dos OSs são mais robustas, conforme pode ser visto na Tabela 10. Encontramos coeficientes negativos e significativos para todos os anos de atuação, exceto para o $12^{\circ}$. Em termos monetários e de porcentagem do PIB, as economias estimadas situam-se entre R $\$ 5,3$ milhões e R\$ 36,5 milhões por ano e $0,1 \%$ e $0,5 \%$ do PIB. Também se verifica um padrão crescente de economias de acordo com o maior tempo de atuação dos OSs até o $8^{\circ}$ ano, o que sugere que a acumulação de experiência é um fator que ajuda na atividade de fiscalização das contas públicas municipais. 
Tabela 7: Impacto dos Observatórios Sociais Sobre Despesas Municipais (3)

\begin{tabular}{|c|c|c|c|c|c|c|c|c|}
\hline & Total & Correntes & Juros & Outras & Pessoal & Capital & Amort. & Invest. \\
\hline OS 1 ano & $\begin{array}{r}-101,488^{*} \\
(51,821)\end{array}$ & $\begin{array}{l}-39,060 \\
(44,355)\end{array}$ & $\begin{array}{r}1,011 \\
(1,461)\end{array}$ & $\begin{array}{r}-63,373^{* *} \\
(31,535)\end{array}$ & $\begin{array}{r}23,303 \\
(29,309)\end{array}$ & $\begin{array}{r}-55,002^{*} \\
(28,409)\end{array}$ & $\begin{array}{l}-0,409 \\
(6,804)\end{array}$ & $\begin{array}{l}-42,564 \\
(30,210)\end{array}$ \\
\hline OS 2 anos & $\begin{array}{r}-41,409 \\
(148,930)\end{array}$ & $\begin{array}{r}-38,399 \\
(128,130)\end{array}$ & $\begin{array}{l}4,598^{* *} \\
(2,284)\end{array}$ & $\begin{array}{l}-61,123 \\
(81,409)\end{array}$ & $\begin{array}{r}18,126 \\
(58,201)\end{array}$ & $\begin{array}{r}6,706 \\
(38,978)\end{array}$ & $\begin{array}{r}1,496 \\
(12,174)\end{array}$ & $\begin{array}{r}23,119 \\
(42,710)\end{array}$ \\
\hline OS 3 anos & $\begin{array}{l}-105,905 \\
(154,451)\end{array}$ & $\begin{array}{r}-74,283 \\
(128,270)\end{array}$ & $\begin{array}{r}5,637 \\
(3,801)\end{array}$ & $\begin{array}{r}-109,964 \\
(80,448)\end{array}$ & $\begin{array}{r}30,043 \\
(63,878)\end{array}$ & $\begin{array}{l}-17,959 \\
(48,895)\end{array}$ & $\begin{array}{r}-2,121 \\
(12,033)\end{array}$ & $\begin{array}{r}5,235 \\
(51,907)\end{array}$ \\
\hline OS 4 anos & $\begin{array}{l}-127,834 \\
(163,685)\end{array}$ & $\begin{array}{r}-47,921 \\
(137,595)\end{array}$ & $\begin{array}{l}8,126^{*} \\
(4,557)\end{array}$ & $\begin{array}{r}-103,751 \\
(86,468)\end{array}$ & $\begin{array}{r}47,704 \\
(76,511)\end{array}$ & $\begin{array}{l}-50,794 \\
(60,319)\end{array}$ & $\begin{array}{r}-6,313 \\
(13,462)\end{array}$ & $\begin{array}{l}-12,462 \\
(57,452)\end{array}$ \\
\hline OS 5 anos & $\begin{array}{l}-133,730 \\
(199,774)\end{array}$ & $\begin{array}{r}-40,271 \\
(160,632)\end{array}$ & $\begin{array}{l}9,020^{*} \\
(5,088)\end{array}$ & $\begin{array}{r}-125,926 \\
(96,902)\end{array}$ & $\begin{array}{r}76,636 \\
(92,526)\end{array}$ & $\begin{array}{l}-72,644 \\
(87,212)\end{array}$ & $\begin{array}{l}-13,015 \\
(14,033)\end{array}$ & $\begin{array}{l}-27,652 \\
(87,296)\end{array}$ \\
\hline OS 6 anos & $\begin{array}{l}-160,180 \\
(232,445)\end{array}$ & $\begin{array}{r}-49,728 \\
(189,052)\end{array}$ & $\begin{array}{c}11,718^{*} \\
(6,330)\end{array}$ & $\begin{array}{l}-148,768 \\
(118,062)\end{array}$ & $\begin{array}{r}87,322 \\
(108,246)\end{array}$ & $\begin{array}{l}-90,061 \\
(90,872)\end{array}$ & $\begin{array}{l}-17,140 \\
(16,273)\end{array}$ & $\begin{array}{l}-29,415 \\
(89,128)\end{array}$ \\
\hline OS 7 anos & $\begin{array}{l}-179,320 \\
(259,713)\end{array}$ & $\begin{array}{r}-23,967 \\
(209,860)\end{array}$ & $\begin{array}{c}13,910^{*} \\
(7,998)\end{array}$ & $\begin{array}{l}-141,499 \\
(129,324)\end{array}$ & $\begin{array}{r}103,623 \\
(117,580)\end{array}$ & $\begin{array}{l}-136,551 \\
(109,491)\end{array}$ & $\begin{array}{l}-15,370 \\
(19,739)\end{array}$ & $\begin{array}{r}-68,750 \\
(109,002)\end{array}$ \\
\hline OS 8 anos & $\begin{array}{l}-137,779 \\
(271,845)\end{array}$ & $\begin{array}{r}-31,519 \\
(224,045)\end{array}$ & $\begin{array}{r}17,724^{*} \\
(9,265)\end{array}$ & $\begin{array}{l}-156,088 \\
(142,876)\end{array}$ & $\begin{array}{r}106,845 \\
(128,886)\end{array}$ & $\begin{array}{r}-84,977 \\
(121,569)\end{array}$ & $\begin{array}{l}-10,743 \\
(23,673)\end{array}$ & $\begin{array}{r}-11,765 \\
(119,470)\end{array}$ \\
\hline OS 9 anos & $\begin{array}{r}-62,119 \\
(309,719)\end{array}$ & $\begin{array}{r}44,650 \\
(242,248)\end{array}$ & $\begin{array}{l}18,582^{*} \\
(10,270)\end{array}$ & $\begin{array}{l}-132,921 \\
(161,151)\end{array}$ & $\begin{array}{r}158,989 \\
(142,098)\end{array}$ & $\begin{array}{r}-79,910 \\
(149,097)\end{array}$ & $\begin{array}{r}-2,589 \\
(30,272)\end{array}$ & $\begin{array}{r}-10,590 \\
(140,511)\end{array}$ \\
\hline OS 10 anos & $\begin{array}{r}-92,820 \\
(353,699)\end{array}$ & $\begin{array}{r}80,010 \\
(278,632)\end{array}$ & $\begin{array}{l}21,750^{*} \\
(11,474)\end{array}$ & $\begin{array}{l}-133,416 \\
(177,788)\end{array}$ & $\begin{array}{r}191,677 \\
(157,494)\end{array}$ & $\begin{array}{l}-137,365 \\
(156,974)\end{array}$ & $\begin{array}{l}-26,185 \\
(39,643)\end{array}$ & $\begin{array}{r}-33,093 \\
(158,160)\end{array}$ \\
\hline OS 11 anos & $\begin{array}{l}-133,606 \\
(397,817)\end{array}$ & $\begin{array}{r}105,424 \\
(313,257)\end{array}$ & $\begin{array}{c}26,790^{* *} \\
(13,243)\end{array}$ & $\begin{array}{l}-110,644 \\
(197,924)\end{array}$ & $\begin{array}{r}189,278 \\
(175,083)\end{array}$ & $\begin{array}{l}-209,505 \\
(176,205)\end{array}$ & $\begin{array}{r}36,624 \\
(35,348)\end{array}$ & $\begin{array}{l}-161,549 \\
(173,574)\end{array}$ \\
\hline OS 12 anos & $\begin{array}{r}-809,987^{*} \\
(447,040)\end{array}$ & $\begin{array}{r}376,023 \\
(359,782)\end{array}$ & $\begin{array}{r}19,480 \\
(12,922)\end{array}$ & $\begin{array}{r}42,610 \\
(223,745)\end{array}$ & $\begin{array}{r}313,933 \\
(193,033)\end{array}$ & $\begin{array}{r}-1.164,119^{* * *} \\
(175,391)\end{array}$ & $\begin{array}{l}-16,554 \\
(34,011)\end{array}$ & $\begin{array}{r}-937,721^{* * *} \\
(178,094)\end{array}$ \\
\hline $\mathrm{N}$ & 4.992 & 4.992 & 4.992 & 4.992 & 4.992 & 4.992 & 4.992 & 4.992 \\
\hline$R^{2}$ & 0,711 & 0,760 & 0,638 & 0,671 & 0,826 & 0,502 & 0,545 & 0,490 \\
\hline
\end{tabular}

Fonte: Elaboração própria. Notas: ${ }^{*} \mathrm{p}<0,1 ;{ }^{* *} \mathrm{p}<0,05 ;{ }^{* * *} \mathrm{p}<0,01$

Controles: efeitos fixos para municípios, anos, prefeitos,interações entre prefeitos e mandatos,

partidos políticos do prefeito, PIB per capita, percentual do valor adicionado em agropecuária,

indústria e serviçoos e tendências lineares por município. Erros-padrão agrupados por município. 
Tabela 8: Impacto dos Observatórios Sociais Sobre Despesas Municipais (4)

\begin{tabular}{cccccccc}
\hline & Consumo & Distribuição & Serv. PF & Serv. PJ & Diárias & Equip. & Obras \\
\hline OS & $-6,949$ & $-5,994$ & 9,178 & $-42,863$ & 7,354 & 8,323 & $-8,121$ \\
& $(14,336)$ & $(4,344)$ & $(9,173)$ & $(33,370)$ & $(8,297)$ & $(9,503)$ & $(28,410)$ \\
\hline $\mathrm{N}$ & 4.992 & 4.992 & 4.992 & 4.992 & 4.992 & 4.992 & 4.992 \\
$\mathrm{R}^{2}$ & 0,605 & 0,736 & 0,534 & 0,683 & 0,707 & 0,408 & 0,406 \\
\hline
\end{tabular}

Fonte: Elaboração própria. Notas: ${ }^{*} \mathrm{p}<0,1 ;{ }^{* *} \mathrm{p}<0,05 ;{ }^{* * *} \mathrm{p}<0,01$

Controles: efeitos fixos para municípios, anos, prefeitos,interações entre prefeitos e mandatos, partidos políticos do prefeito, PIB per capita, percentual do valor adicionado em agropecuária, indústria e serviçoos e tendências lineares por município. Erros-padrão agrupados por município.

Tabela 9: Impacto dos Observatórios Sociais Sobre Despesas Municipais (5)

\begin{tabular}{lccccccc}
\hline & Consumo & Distribuição & Serv. PF & Serv. PJ & Diárias & Equip. & Obras \\
\hline OS (anos) & $-5,096$ & $-2,684$ & 1,772 & $-13,243$ & 2,430 & $9,042^{* *}$ & 11,048 \\
& $(4,969)$ & $(2,020)$ & $(4,724)$ & $(15,826)$ & $(1,506)$ & $(4,369)$ & $(11,013)$ \\
\hline $\mathrm{N}$ & 4.992 & 4.992 & 4.992 & 4.992 & 4.992 & 4.992 & 4.992 \\
$\mathrm{R}^{2}$ & 0,605 & 0,736 & 0,534 & 0,683 & 0,706 & 0,408 & 0,406 \\
\hline Fonte: Elaboração própria. Notas: ${ }^{*} \mathrm{p}<0,1 ;{ }^{* *} \mathrm{p}<0,05 ;{ }^{* * *} \mathrm{p}<0,01$ \\
Controles: efeitos fixos para municípios, anos, prefeitos,interações entre prefeitos e \\
mandatos, partidos políticos do prefeito, PIB per capita, percentual do valor \\
adicionado em agropecuária, indústria e serviçoos e tendências lineares por \\
município. Erros-padrão agrupados por município.
\end{tabular}

Nossos resultados podem ser comparados com os encontrados no trabalho de Caldas et al. (2016), no qual, a partir dos relatórios do Programa de Fiscalização por Sorteios Públicos da CGU, estimam o impacto da corrupção sobre as despesas municipais em diferentes funções de governo (assistência social, educação, saúde, outras despesas e despesas totais). Os autores documentam que maiores níveis de corrupção possuem impacto positivo nas despesas relacionadas à educação e saúde e relacionam esse resultado ao modelo de aplicação de recursos que, constitucionalmente, obriga os municípios a gastarem, no mínimo, $40 \%$ de suas receitas nessas duas funções $(25 \%$ para educação e $15 \%$ para saúde). Adicionalmente, a Lei de Responsabilidade Fiscal limita os gastos municipais com pessoal a $60 \%$ da receita. Assim, conforme argumentam, criam-se incentivos para a busca de rendas por meio de uma maior alocação de recursos públicos em bens de capital e custeio e na contratação de serviços. Esse resultado, combinado à evidência de que a corrupção afeta negativamente a qualidade dos serviços públicos (Ferraz et al. 2012) permite resumir o efeito real da corrupção como: "fazer menos com mais recursos". Nossos resultados indicam que o monitoramento da gestão pública feito pelos OSs mostra-se capaz de reverter pelo menos parte dessa ineficiência ao proporcionar economias em rubricas indicadas como entre as mais prováveis que ocorram desvios: material de consumo e contratação de serviços.

Outra comparação interessante pode ser feita com outros estudos internacionais que enfocaram o mesmo assunto. Em uma análise experimental conduzida na Indonésia (Olken 2007), não foram encontrados efeitos significativos da inspeção da comunidade local em projetos de obras públicas. Outra análise experimental conduzida em Uganda (Björkman \& Svensson 2009) encorajou 
Tabela 10: Impacto dos Observatórios Sociais Sobre Despesas Municipais (6)

\begin{tabular}{|c|c|c|c|c|c|c|c|}
\hline & Consumo & Distribuição & Serv. PF & Serv. PJ & Diárias & Equip. & Obras \\
\hline OS 1 ano & $\begin{array}{r}-11,485^{* * *} \\
(4,194)\end{array}$ & $\begin{array}{l}-5,455 \\
(8,341)\end{array}$ & $\begin{array}{r}9,141 \\
(26,313)\end{array}$ & $\begin{array}{r}-40,825^{* * *} \\
(9,654)\end{array}$ & $\begin{array}{r}9,412 \\
(9,991)\end{array}$ & $\begin{array}{r}13,996 \\
(29,073)\end{array}$ & $\begin{array}{l}-24,478 \\
(42,075)\end{array}$ \\
\hline OS 2 anos & $\begin{array}{l}-6,275 \\
(7,425)\end{array}$ & $\begin{array}{l}-12,415 \\
(16,985)\end{array}$ & $\begin{array}{r}14,400 \\
(80,310)\end{array}$ & $\begin{array}{r}-57,072^{* * *} \\
(6,745)\end{array}$ & $\begin{array}{r}7,690 \\
(14,013)\end{array}$ & $\begin{array}{r}22,252 \\
(39,443)\end{array}$ & $\begin{array}{r}48,351 \\
(56,345)\end{array}$ \\
\hline OS 3 anos & $\begin{array}{r}-22,318^{* * *} \\
(8,635)\end{array}$ & $\begin{array}{l}-12,828 \\
(22,709)\end{array}$ & $\begin{array}{r}6,347 \\
(75,203)\end{array}$ & $\begin{array}{r}-63,118^{* * *} \\
(7,730)\end{array}$ & $\begin{array}{r}9,561 \\
(16,084)\end{array}$ & $\begin{array}{r}20,260 \\
(46,154)\end{array}$ & $\begin{array}{r}48,927 \\
(66,448)\end{array}$ \\
\hline OS 4 anos & $\begin{array}{l}-9,139 \\
(9,967)\end{array}$ & $\begin{array}{l}-15,301 \\
(22,962)\end{array}$ & $\begin{array}{r}9,821 \\
(82,209)\end{array}$ & $\begin{array}{r}-62,332^{* * *} \\
(8,991)\end{array}$ & $\begin{array}{r}11,270 \\
(18,130)\end{array}$ & $\begin{array}{r}29,928 \\
(55,525)\end{array}$ & $\begin{array}{r}49,449 \\
(78,944)\end{array}$ \\
\hline OS 5 anos & $\begin{array}{r}-16,844^{*} \\
(10,231)\end{array}$ & $\begin{array}{l}-12,325 \\
(25,683)\end{array}$ & $\begin{array}{r}11,871 \\
(93,335)\end{array}$ & $\begin{array}{r}-88,321^{* * *} \\
(10,595)\end{array}$ & $\begin{array}{r}14,258 \\
(24,858)\end{array}$ & $\begin{array}{r}31,759 \\
(71,796)\end{array}$ & $\begin{array}{r}46,688 \\
(93,061)\end{array}$ \\
\hline OS 6 anos & $\begin{array}{r}-40,501^{* * *} \\
(12,865)\end{array}$ & $\begin{array}{l}-13,647 \\
(29,544)\end{array}$ & $\begin{array}{r}12,143 \\
(104,947)\end{array}$ & $\begin{array}{r}-97,130^{* * *} \\
(11,036)\end{array}$ & $\begin{array}{r}16,528 \\
(28,349)\end{array}$ & $\begin{array}{r}57,910 \\
(75,557)\end{array}$ & $\begin{array}{r}50,956 \\
(112,958)\end{array}$ \\
\hline OS 7 anos & $\begin{array}{r}-43,733^{* * *} \\
(13,918)\end{array}$ & $\begin{array}{l}-15,643 \\
(32,441)\end{array}$ & $\begin{array}{r}16,473 \\
(110,605)\end{array}$ & $\begin{array}{r}-85,534^{* * *} \\
(11,789)\end{array}$ & $\begin{array}{r}18,747 \\
(33,951)\end{array}$ & $\begin{array}{r}66,989 \\
(85,734)\end{array}$ & $\begin{array}{r}26,484 \\
(127,279)\end{array}$ \\
\hline OS 8 anos & $\begin{array}{r}-50,086^{* * *} \\
(14,908)\end{array}$ & $\begin{array}{l}-20,783 \\
(35,337)\end{array}$ & $\begin{array}{r}18,013 \\
(132,166)\end{array}$ & $\begin{array}{r}-174,214^{* * *} \\
(12,585)\end{array}$ & $\begin{array}{r}21,126 \\
(37,271)\end{array}$ & $\begin{array}{r}84,420 \\
(97,348)\end{array}$ & $\begin{array}{r}90,456 \\
(141,971)\end{array}$ \\
\hline OS 9 anos & $\begin{array}{r}-59,533^{* * *} \\
(18,061)\end{array}$ & $\begin{array}{l}-26,561 \\
(38,388)\end{array}$ & $\begin{array}{r}25,228 \\
(134,085)\end{array}$ & $\begin{array}{r}-47,154^{* * *} \\
(14,583)\end{array}$ & $\begin{array}{r}25,278 \\
(45,504)\end{array}$ & $\begin{array}{r}114,877 \\
(106,617)\end{array}$ & $\begin{array}{r}92,195 \\
(164,973)\end{array}$ \\
\hline OS 10 anos & $\begin{array}{r}-82,856^{* * *} \\
(19,565)\end{array}$ & $\begin{array}{l}-38,232 \\
(43,053)\end{array}$ & $\begin{array}{r}15,470 \\
(151,582)\end{array}$ & $\begin{array}{r}-77,939^{* * *} \\
(15,815)\end{array}$ & $\begin{array}{r}29,035 \\
(47,118)\end{array}$ & $\begin{array}{r}133,382 \\
(125,295)\end{array}$ & $\begin{array}{r}64,213 \\
(214,311)\end{array}$ \\
\hline OS 11 anos & $\begin{array}{r}-64,719^{* * *} \\
(22,324)\end{array}$ & $\begin{array}{l}-40,126 \\
(47,638)\end{array}$ & $\begin{array}{r}15,286 \\
(158,178)\end{array}$ & $\begin{array}{r}-46,691^{* * *} \\
(16,623)\end{array}$ & $\begin{array}{r}32,620 \\
(54,300)\end{array}$ & $\begin{array}{r}118,088 \\
(135,022)\end{array}$ & $\begin{array}{r}26,789 \\
(269,975)\end{array}$ \\
\hline OS 12 anos & $\begin{array}{r}-153,301^{* * *} \\
(25,262)\end{array}$ & $\begin{array}{r}-8,927 \\
(57,112)\end{array}$ & $\begin{array}{r}75,814 \\
(198,606)\end{array}$ & $\begin{array}{r}138,312^{* * *} \\
(18,928)\end{array}$ & $\begin{array}{r}29,444 \\
(58,270)\end{array}$ & $\begin{array}{r}-14,763 \\
(140,344)\end{array}$ & $\begin{array}{l}-493,053 \\
(515,412)\end{array}$ \\
\hline $\mathrm{N}_{2}$ & 4.992 & 4.992 & 4.992 & 4.992 & 4.992 & 4.992 & 4.992 \\
\hline$R^{2}$ & 0,606 & 0,736 & 0,534 & 0,684 & 0,709 & 0,408 & 0,407 \\
\hline $\begin{array}{l}\text { Fonte: } \\
\text { Control } \\
\text { prefeito } \\
\text { percent } \\
\text { tendên }\end{array}$ & ineare & oria Not & $* n<0$ & $* * * 0$ & $* * * \mathrm{n}$ & 01 & 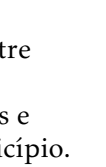 \\
\hline
\end{tabular}


Tabela 11: Economia Proporcionada pelos Observatórios Sociais em Despesas Municipais (7)

\begin{tabular}{ccccc}
\hline & \multicolumn{2}{c}{ Consumo } & \multicolumn{2}{c}{ Serviços PJ } \\
\hline Anos & R\$ Milhões & $\%$ PIB & R\$ Milhões & $\%$ PIB \\
\hline 1 & 1,49 & 0,03 & 5,29 & 0,10 \\
2 & - & - & 7,51 & 0,14 \\
3 & 3,22 & 0,05 & 9,12 & 0,15 \\
4 & - & - & 9,42 & 0,16 \\
5 & - & - & 13,53 & 0,26 \\
6 & 6,47 & 0,12 & 15,53 & 0,28 \\
7 & 8,08 & 0,12 & 15,80 & 0,24 \\
8 & 10,48 & 0,14 & 36,46 & 0,50 \\
9 & 12,74 & 0,17 & 10,09 & 0,14 \\
10 & 14,93 & 0,24 & 14,04 & 0,22 \\
11 & 14,7 & 0,16 & 10,61 & 0,12 \\
12 & 56,07 & 0,38 & - & - \\
\hline Média & 14,2 & 0,2 & 13,4 & 0,2 \\
\hline Fonte: Elaboração própria. & & &
\end{tabular}

a participação em ambientes comunitários para aumentar o envolvimento da população com o estado da prestação de serviços de saúde e a capacidade de responsabilizar os provedores locais por seu desempenho. Os resultados documentam um aumento da utilização de serviços de saúde, redução da mortalidade infantil e aumento do peso das crianças. Finalmente, outro estudo envolvendo reuniões comunitárias convocadas por representantes do governo local na Índia documenta uma maior participação nessas reuniões de membros de grupos sociais desprivilegiados e um melhor enfoque de programas sociais nas localidades onde esses encontros ocorrem (Besley et al. 2005). Assim, os resultados experimentais sobre a efetividade de iniciativas privadas no monitoramento do serviço público apontam em diferentes direções, sugerindo que o contexto no qual essas atividades são desenvolvidas pode influenciar na produção de diferentes resultados (Björkman \& Svensson 2010).

\section{Conclusão}

Neste artigo, examinamos a questão da efetividade da iniciativa popular no monitoramento e na melhoria da qualidade da gestão fiscal dos municípios no estado do Paraná. Concretamente, estudamos o caso da rede OSB e avaliamos o impacto da implementação de unidades locais nas despesas municipais, totais e desagregadas por diferentes rubricas.

Para identificar o efeito causal dos OSs sobre as despesas municipais, exploramos a introdução gradual das unidades nos municípios no período 2006 - 2017. Nesse período, os OSs se instalaram em 36 municípios em diferentes anos, o que nos permite usar uma estratégia de diferenças-em-diferenças para isolar o efeito dos OSs de outras características não observáveis dos municípios que afetem tanto a instalação quanto a administração.

As atividades dos OSs se concentram basicamente no combate à corrupção por meio do monitoramento de processos de licitação dos municípios e de outras frentes de atuação. Os resultados mostram economias em algumas rubricas de despesas municipais: despesas de capital e investimentos de despesas 
Controle social da administração pública por agentes privados: avaliando o impacto dos observatórios sociais nas despesas dos municípios do Paraná 111

correntes em material de consumo e serviços contratados de pessoas jurídicas, sendo estas duas últimas as que apresentaram resultados mais robustos. A análise também encontra evidências de que o tempo acumulado de experiência favorece a obtenção de resultados, uma vez que economias maiores são obtidas com mais tempo de atuação de uma unidade dos OSs nos municípios.

Esses resultados são relevantes na medida em que complementam evidências acumuladas para o Brasil de que a corrupção nos municípios reduz a qualidade dos serviços públicos prestados e, ao mesmo tempo, infla as despesas (Ferraz et al. 2012, Caldas et al. 2016). Assim, nosso estudo traz evidências de que o monitoramento de contas públicas como forma de combate à corrupção pode ajudar a corrigir um de efeitos colaterais perniciosos. Adicionalmente, trazemos evidências de que a iniciativa social, independente do poder público, pode também contribuir nessa tarefa de fiscalização da gestão dos municípios, desafiando uma tradicional falha de mercado associada à produção de bens públicos.

Por fim, nosso trabalho também contrasta com a literatura que examina o efeito de iniciativas populares no monitoramento e responsabilização de agentes públicos na condução das atividades da administração, assim com a literatura que aponta a insuficiência da oferta de bens públicos pela iniciativa privada. Uma diferença marcante entre nosso estudo e os outros é o contexto em que ocorrem as iniciativas de monitoramento da gestão. Enquanto outros estudos examinam intervenções experimentais em pequenas comunidades pobres, nosso estudo examina uma organização de grande alcance e atuação em municípios com maior nível de desenvolvimento econômico e institucional. Nossos resultados apontam para a efetividade da atuação da iniciativa privada na provisão do serviço de fiscalização de despesas públicas, no contexto de administrações locais. Em um contexto de maior escassez de recursos, esse resultado aponta para a relevância do controle social como forma de aumentar a eficiência na gestão pública. No entanto, esses resultados não dizem nada a respeito do nível ótimo de provimento dessas atividades, nem podem ser generalizados para outros níveis da administração pública (estados e união) ou de outros poderes (legislativo e judiciário). Também não podemos afirmar nada quanto à influência da atividade dos OSs sobre a qualidade dos serviços prestados, que tende a ser negativamente afetada pela corrupção. Ainda assim, nosso estudo traz uma contribuição relevante para a literatura que trata do monitoramento privado da administração pública, sendo o primeiro a estimar quantitativamente o impacto dos OSs sobre despesas públicas municipais.

\section{Agradecimentos}

Agradecemos os comentários de Mariana Fialho, Ricardo Ramalhete, Ana Carolina Giuberti, Edson Zambon e Guilherme Pereira e assistência de pesquisa de Juliana Sena e Manuela Hirata. Letícia Cardoso forneceu informações úteis sobre as datas de início de operações dos Observatórios Sociais. Os erros remanescentes são de responsabilidade dos autores.

\section{Referências Bibliográficas}

Aidt, T. S. (2003). Economic analysis of corruption: a survey. The Economic Journal, London, v. 113, n. 491, p. 632-652. 
Arellano, M. (1987). Computing robust standard errors for within-groups estimators. Oxford Bulletin of Economics and Statistics, Oxford, v. 49, n. 4, p. 431-434.

Banerjee, A., Mullainathan, S. \& Hanna, R. (2013). Corruption. In: GIBBONS, R.; ROBERTS, J. (orgs.) The Handbook of Organizational Economics. Princeton: Princeton University Press. p. 1109-1147.

Battisti, M., Lavezzi, A. M., Masserini, L. \& Pratesi, M. (2018). Resisting the extortion racket: an empirical analysis. European Journal of Law and Economics, Cham, v. 46, n. 1, p. 1-37.

Becker, G. S. \& Stigler, G. J. (1974). Law enforcement, malfeasance, and compensation of enforcers. The Journal of Legal Studies, Chicago, v. 3, n. 1, p. $1-18$.

Bergstrom, T., Blume, L. \& Varian, H. (1986). On the private provision of public goods. Journal of Public Economics, Amsterdam, v. 29, n. 1, p. 25-49.

Bertrand, M., Duflo, E. \& Mullainathan, S. (2004). How much should we trust differences-in-differences estimates? The Quarterly Journal of Economics, Cambridge, v. 119, n. 1, p. 249-275.

Besley, T., Pande, R. \& Rao, V. (2005). Participatory democracy in action: survey evidence from South India. Journal of the European Economic Association, Oxford, v. 3, n. 2-3, p. 648-657.

Björkman, M. \& Svensson, J. (2009). Power to the people: evidence from a randomized field experiment on community-based monitoring in Uganda. The Quarterly Journal of Economics, Cambridge, v. 124, n. 2, p. 735-769.

Björkman, M. \& Svensson, J. (2010). When is community-based monitoring effective? Evidence from a randomized experiment in primary health in Uganda. Journal of the European Economic Association, Oxford, v. 8, n. 2-3, p. 571-581.

Bona, R. S. \& Boeira, S. L. (2018). Observatório Social do Brasil e os desafios organizacionais do controle social. Cadernos Gestão Pública e Cidadania, São Paulo, v. 23, n. 75.

Brollo, F., Nannicini, T., Perotti, R. \& Tabellini, G. (2013). The political resource curse. American Economic Review, Nashville, v. 103, n. 5, p. 17591796.

Burai, P. (2020). Overcoming the pitfalls of engaging communities in anti-corruption programmes. Bergen: Chr. Michelsen Institute. Disponível em: https://www.u4.no/publications overcoming-the-pitfalls-of-engagingcommunities-in-anti-corruption-programmes.

Caldas, O. V., Costa, C. M. \& Pagliarussi, M. S. (2016). Corrupção e composição dos gastos governamentais: evidências a partir do Programa de Fiscalização por Sorteios Públicos da Controladoria-Geral da União. Revista de Administração Pública, Rio de Janeiro, v. 50, n. 2, p. 237-264. 
Controle social da administração pública por agentes privados: avaliando o impacto dos observatórios sociais nas despesas dos municípios do Paraná 113

Campos, F. A. O., Castelar, I. \& Soares, R. B. (2018). Fatores associados à corrupção municipal em transferências de recursos da União. Nova Economia, Belo Horizonte, v. 28, n. 3, p. 879-911.

Campos, F. d. A. O. \& Pereira, R. A. (2016). Corrupção e ineficiência no Brasil: uma análise de equilíbrio geral. Estudos Econômicos, São Paulo, v. 46, n. 2, p. 373-408.

Di, Tella, R. \& Schargrodsky, E. (2003). The role of wages and auditing during a crackdown on corruption in the city of Buenos Aires. The Journal of Law and Economics, Chicago, v. 46, n. 1, p. 269-292.

Dixit, A. (2018). Anti-corruption institutions: Some history and theory. In: BASU, K.; CORDELLA, T. (orgs.) Institutions, governance and the control of corruption. Cham: Palgrave Macmillan. p. 15-49.

Favretto, J. \& Riccio, E. L. (2017). Observatório Social do Brasil em números. E-book. Disponível em: http://osbrasil.org.br/wpcontent/uploads/2017/04/e-book-OSB-06-04-2017-2.pdf.

Ferraz, C. \& Finan, F. (2008). Exposing corrupt politicians: the effects of Brazil's publicly released audits on electoral outcomes. The Quarterly Journal of Economics, Cambridge, v. 123, n. 2, p. 703-745.

Ferraz, C. \& Finan, F. (2011). Electoral accountability and corruption: evidence from the audits of local governments. American Economic Review, Nashville, v. 101, n. 4, p. 1274-1311.

Ferraz, C., Finan, F. \& Moreira, D. B. (2012). Corrupting learning: evidence from missing federal education funds in Brazil. Journal of Public Economics, Amsterdam, v. 96, n. 9-10, p. 712-726.

Imbens, G. W. \& Wooldridge, J. M. (2009). Recent developments in the econometrics of program evaluation. Journal of Economic Literature, Nashville, v. 47 , n. 1, p. $5-86$.

Lewis, B. D. (2017). Local government spending and service delivery in Indonesia: the perverse effects of substantial fiscal resources. Regional Studies, London, v. 51, n. 11, p. 1695-1707.

Michener, G., Contreras, E. \& Niskier, I. (2018). From opacity to transparency? Evaluating access to information in Brazil five years later. Revista de Administração Pública, Rio de Janeiro, v. 52, n. 4, p. 610-629.

Moe, T. (2013). Delegation, control, and the study of public bureaucracy. In: GIBBONS, R.; ROBERTS, J. (orgs.) The Handbook of Organizational Economics. Princeton: Princeton University Press. v. 10, n. 2.

Oliva, F. (2012). A experiência do Norte de Minas. In: VERILlO, J.; VERILlO, N. (orgs.) O Combate à Corrupção nas Prefeituras do Brasil. São Paulo: 24X7 Cultural. p. 81-83.

Olken, B. A. (2007). Monitoring corruption: evidence from a field experiment in Indonesia. Journal of Political Economy, Chicago, v. 115, n. 2, p. 200249. 
Olken, B. A. \& Pande, R. (2012). Corruption in developing countries. Annual Review of Economics, Palo Alto, v. 4, n. 1, p. 479-509.

PNUD, IPEA \& FJP (2013). O Índice de Desenvolvimento Humano Municipal Brasileiro. Brasília: PNUD.

Reinikka, R. \& Svensson, J. (2011). The power of information in public services: evidence from education in Uganda. Journal of Public Economics, Amsterdam, v. 95, n. 7-8, p. 956-966.

Rocha, D. G., Zuccolotto, R. \& Teixeira, M. A. C. (2020). Insulated and undemocratic: the (im) possibility of social accountability in Brazilian courts of accounts. Revista de Administração Pública, Rio de Janeiro, v. 54, n. 2, p. 201-219.

Samuelson, P. A. (1954). The pure theory of public expenditure. The Review of Economics and Statistics, Cambridge, v. 36, n. 4, p. 387-389.

Superti, C. (2009). Addiopizzo: can a label defeat the Mafia? Journal of International Policy Solutions, La Jolla, v. 11, n. 4, p. 3-11.

Van Rijckeghem, C. \& Weder, B. (2001). Bureaucratic corruption and the rate of temptation: do wages in the civil service affect corruption, and by how much? Journal of Development Economics, Amsterdam, v. 65, n. 2, p. 307-331.

Zuccolotto, R. \& Teixeira, M. A. C. (2019). Transparência: aspectos conceituais e avanços no contexto brasileiro. Brasília: ENAP. 